\title{
Evidence for fungal proliferation following the Cretaceous/Paleogene mass-extinction event, based on chemostratigraphy in the Raton and Powder River basins, western North America
}

\author{
KEITH BERRY \\ Science Department, Hoehne Re-3 School District, Hoehne, Colorado, 81046, U.S.A.; \\ e-mail: keith.berry@hoehnesd.org
}

Received 1 December 2019; accepted for publication 29 May 2020

\begin{abstract}
The presence of the amino acid $\alpha$-aminoisobutyric acid (Aib) within Cretaceous/Paleogene (K/Pg) boundary clay in the Raton and Powder River basins in Colorado and Wyoming, respectively, has been described as compelling evidence that extraterrestrial Aib survived the high-energy Chicxulub impact. Based on contemporary experiments and simulations, however, it is highly unlikely that extraterrestrial Aib survived the impact, which had peak impact pressures and temperatures in excess of $600 \mathrm{GPa}$ and 10,000 K, respectively. In other words, the amino acid signature of the carbonaceous chondritic asteroid that impacted Chicxulub was undoubtedly destroyed upon impact during formation of the vapor plume or so-called "fireball." The only organisms known to produce Aib are the suite (more than 30 genera) of cosmopolitan saprotrophic filamentous fungi that include Trichoderma Pers., which has recently been hypothesized to have thrived during the K/Pg mass-extinction event. Therefore it is proposed that the Aib horizon in the K/Pg boundary clay in the Raton and Powder River basins correlates with the K/Pg boundary fungal spike, which thus far has only been observed in New Zealand (Southern Hemisphere). This proposition is based upon superimposing the Aib horizon on the well-known iridium and fern-spore spikes, as its stratigraphic position precisely matches that predicted by the fungal spike. If correct, this hypothesis alters the conventional perspective on the tempo and mode of terrestrial ecosystem recovery in western North America, as the heavily sampled K/Pg boundary section in the Raton Basin was instrumental in shaping the traditional narrative of the rapid recolonization of a denuded landscape by ferns via wind-blown spores in the immediate wake of regional deforestation caused by the K/Pg impact event. Perhaps more importantly, it could present an alternative to traditional palynological approaches for locating the fungal spike in other terrestrial $\mathrm{K} / \mathrm{Pg}$ boundary sections and could provide additional support for the generalization that global mass-extinction events are frequently accompanied by fungal spikes.
\end{abstract}

KEYWORDS: mass extinctions, K/Pg boundary, fungal spike, Chicxulub, Raton Basin, Powder River Basin

\section{INTRODUCTION}

Organic molecules in asteroids or comets traditionally were thought not to survive impacts if the impactor's diameter and velocity are greater than about $100 \mathrm{~m}$ and $10 \mathrm{~km} / \mathrm{s}$, respectively (Whittet, 1997). Therefore, the detection of the "extraterrestrial" amino acid $\alpha$-aminoisobutyric acid (Aib) near the Cretaceous/Paleogene (K/Pg) boundary (Zhao and Bada, 1989) presented an obvious conundrum if this amino acid was delivered to the Earth's surface by an asteroid or comet impact (Zahnle and Grinspoon, 1990; Mita et al., 1996). Zahnle and Grinspoon (1990) proposed that Aib had been deposited on the Earth's surface by the passage of the Earth through a cometary dust cloud - a short-lived perspective, given the association of the K/Pg impact with the Chicxulub crater in the following year (Hildebrand 
et al., 1991). The Chicxulub asteroid impact at the $\mathrm{K} / \mathrm{Pg}$ boundary generated peak shock pressures greater than $600 \mathrm{GPa}$, coupled with plasma-forming temperatures in excess of $10,000 \mathrm{~K}$, which is hotter than the surface of the sun (Kring and Durda, 2002; Ohno et al., 2014). The consensus among contemporary researchers is that the Chicxulub impactor was a carbonaceous chondritic asteroid (Kyte, 1998; Shukolyukov and Lugmair, 1998; Trinquier et al., 2006; Quitté et al., 2007; Goderis et al., 2013), which should have had a proportionally high composition of extraterrestrial Aib (Zhao and Bada, 1989; Pierazzo and Chyba, 2006). However, even modern simulations and experiments reveal that amino acids present within the Chicxulub asteroid, including Aib, should have been completely destroyed by the high-energy Chicxulub impact (Fig. 1) (Pierazzo and Chyba, 2006; Trigo-Rodríguez, 2006; Bertrand et al., 2009; Cooper et al., 2013; Sugahara and Mimura, 2014). This is because amino acids within the impactor would have been subjected to pyrolysis during formation of the rapidly expanding vapor plume or socalled "fireball" (Pierazzo and Melosh, 2000; Sugahara and Mimura, 2014). For this reason, contemporary researchers still regard deposition of extraterrestrial Aib in the K/Pg boundary clay layer as a mere possibility rather than a certainty (Kring and Durda, 2002). This perspective might be different if the $\mathrm{K} / \mathrm{Pg}$ impactor was a comet rather than a carbonaceous chondritic asteroid (Pierazzo and Chyba, 1999, 2006; Oró et al., 2006; Martins et al., 2013), but, again, this neither appears to be the case nor guarantees that amino acids survived the K/Pg impact. Pierazzo and Melosh (2000) simulated the Chicxulub impact under a variety of conditions and calculated that the minimum shock pressure experienced by both leading and trailing particles in the impactor exceeded 30-35 GPa (Fig. 1), which is the range of shock in which Aib is completely destroyed in experiments (Trigo-Rodríguez, 2006; Bertrand et al., 2009; Sugahara and Mimura, 2014). Likewise, Pierazzo and Chyba (1999) concluded that amino acids simply could not survive an asteroid impact of this magnitude.

At the same time, however, Pierazzo and Chyba (1999: 909) confirmed an earlier, unpublished report by Moore (1996) that Aib was present within the K/Pg boundary clay within the Raton Basin by acknowledging "the discovery
(T. Bunch, pers. comm.) of $\alpha$-aminoisobutyric acid within the boundary layer at the K/T Sussex and Raton Basin sites." Theodore Bunch, who collected the $\mathrm{K} / \mathrm{Pg}$ boundary samples, gave them to his colleague Arthur Weber for ion-exchange chromatography as described by Weber (1998) and Becker et al. (2000). Weber's (1998: 2) analyses, which achieved "femtomole sensitivity," detected low concentrations of Aib in the Raton (Starkville) and Powder River (Sussex) basin localities (Pierazzo and Chyba, 1999; Becker et al., 2000). Becker et al. (2000: 2982) concluded, "abiotic amino acids, $\alpha$-aminoisobutyric (...) have been reported in some (...) continental KTB [Cretaceous/Tertiary boundary] deposits (Art Webber [sic], personal communication). The survivability of fullerenes with trapped noble gases and $\alpha$-aminoisobutyric acid in KTB sediments (...) is indeed unexpected and suggests that exogenous delivery of 'intact' organic material to the surfaces of planets may be more favorable then [sic] has previously been assumed." Similarly, Pierazzo and Chyba (1999: 909) described the presence of Aib in the K/Pg boundary clay at Starkville and Sussex as evidence "that delivery of intact organics in large impacts might be possible." In fact, according to Pierazzo and Chyba (2006: 141 ), the presence of Aib in the K/Pg boundary clay at the Starkville and Sussex localities led them to question the common assumption that amino acids are destroyed by large impacts: "Organic survival in large impacts has

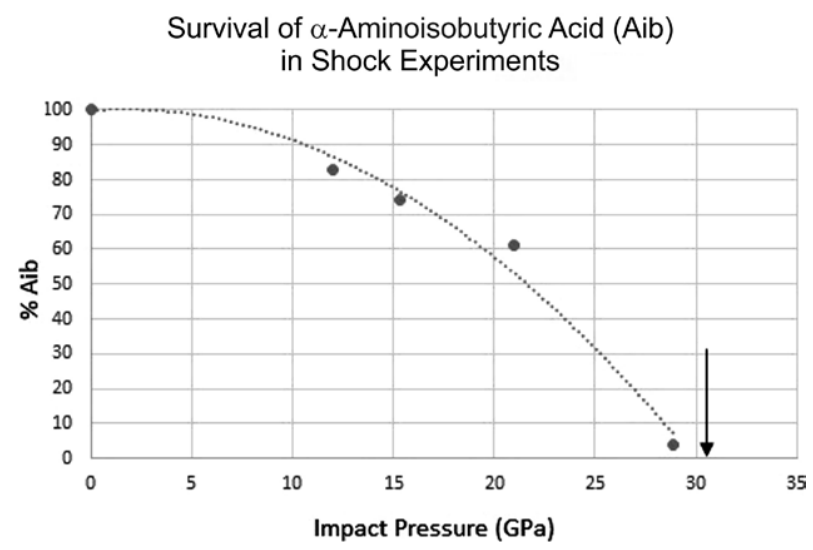

Fig.1. Experimental data collected by Bertrand et al. (2009), Cooper et al. (2013) and Sugahara and Mimura (2014) reveal that Aib present in carbonaceous chondritic meteorites is completely destroyed at relatively low shock pressures ( $230-35 \mathrm{GPa})$. Graph adapted from the data of Bertrand et al. (2009). Arrow indicates the shock pressure at which no Aib survived according to the experimental work of Sugahara and Mimura (2014). These results also agree with the preliminary work of Cooper et al. (2013), who observed that less than $1 \%$ of Aib survived shocks greater than $18 \mathrm{GPa}$ 
received new life from a combination of theoretical and experimental studies. Early incentive was provided by the identification of (...) $\alpha$-aminoisobutyric acid (...) at the Ir-rich Cretaceous/Tertiary (K/T) boundary layer at Sussex and Raton Basin sites." During this time, Brisman et al. (2001) also investigated the presence of Aib in the K/Pg boundary clay at Starkville. However, they were only able to detect amino acids using gas chromatography if they had a concentration of $0.1 \mathrm{nmol} / \mathrm{g}(100 \mathrm{pmol} / \mathrm{g})$ or greater (Brisman et al., 2001), which explains why they failed to detect Aib in the K/Pg boundary clay in the Raton Basin, given that the contemporary analyses published by Pierazzo and Chyba (1999), Becker et al. (2000) and Pierazzo and Chyba (2006) were far more sensitive and could detect concentrations of Aib lower than $0.01 \mathrm{nmol} / \mathrm{g}$ (Weber, 1998). In any case, the presence of Aib in the K/Pg boundary clay in the Raton and Powder River basins ultimately led Pierazzo and Chyba (2006) to conclude that Aib somehow survived the high-energy Chicxulub impact event.

A potentially elegant solution to this conundrum has emerged in the last decade. The perspective that Aib is rarely found in the Earth's biosphere except when introduced by meteoritic sources, such as asteroids or comet impacts, is no longer generally accepted (Brückner et al., 2009; Elsila et al., 2011; Röhrich et al., 2012). Within the biosphere, Aib is known to be produced exclusively by saprotrophic filamentous fungi that are both "ubiquitous and cosmopolitan, even occurring in marine, Arctic and Antarctic regions" (Röhrich et al., 2012: 1221). More than 30 genera containing a vast number of species are now known to produce Aib (Brückner et al., 2009; Brückner et al., 2019), and this number is ever-increasing (Röhrich et al., 2012, 2014). Among the most common and speciose genera known to produce Aib today is the genus Trichoderma Pers. (Hypocreaceae Fr.) (Brückner et al., 2009; Röhrich et al., 2014). Therefore, techniques for distinguishing between biotically and abiotically produced amino acids have been developed (Elsila et al., 2011). This includes determining stable carbon and nitrogen isotopic composition, among other observations such as the presence of L-configuration, a specific stereochemical or spatial arrangement of atoms around the chirality center of the molecule that is typical of living systems (Elsila et al., 2011). Brisman et al.
(2001) sought to use these techniques to determine whether Aib and other amino acids in the $\mathrm{K} / \mathrm{Pg}$ boundary section in the Raton Basin were abiotic or biotic in origin; however, their results were inconclusive because they were unable to isolate or identify Aib in the section (Brisman et al., 2001) - a problem described in greater detail in the previous paragraph.

Despite arguably having the most complete $\mathrm{K} / \mathrm{Pg}$ boundary sections in the world (Nichols and Johnson, 2008; Lyson et al., 2019), western North America apparently has no record of the K/Pg boundary fungal spike like that observed in the Southern Hemisphere (Vajda and McLoughlin, 2007). The fungal spike is interpreted to signal an episode of fungal proliferation during an early post-impact, non-photosynthetic phase of terrestrial ecosystem recovery when fungal saprotrophs thrived by feeding on decaying organic matter in the immediate wake of the K/Pg mass-extinction event (Vajda and McLoughlin, 2004). This earliest phase of terrestrial ecosystem recovery is inferred to have taken place during a global impact winter, when sunlight was blocked by stratospheric soot and sulfate aerosols produced by the Chicxulub asteroid impact (Vajda and McLoughlin, 2004; Vajda et al., 2015; Bercovici and Vellekoop, 2017). The apparent absence of evidence for a fungal spike in the palynological record of western North America has been suggested to be due to any number of factors, including a lack of millimeter-scale microstratigraphic sampling (Vajda and McLoughlin, 2007), the possibility that plant detritus may have been rapidly buried by impact ejecta which inhibited fungi from thriving (Vajda and McLoughlin, 2007), or that earthworms rather than fungi were the predominant saprotrophs at the $\mathrm{K} / \mathrm{Pg}$ boundary in western North America (Chin et al., 2013; Bercovici and Vellekoop, 2017).

In this study I suggest that a western North American fungal spike may be recorded in the Aib signature of the K/Pg boundary clay, such as at Starkville South or Sussex, Wyoming (Fig. 2). Brückner et al. (2009) and Elsila et al. (2011) have implored researchers to question whether claims of extraterrestrial Aib in ancient sediments are instead the result of fungal contamination or the presence of durable Aib-rich peptaibols, which are produced by common soil fungi such as Trichoderma (Brückner et al., 2009; Röhrich et al., 2014; Brückner et al., 2019). Although Brückner et al. (2009) 
point out that it may be difficult or impossible to differentiate between ancient and modern Aib in sediments, the results of recent phylogenetic and genomic studies conducted by Kubicek et al. (2019) support the contention that Aib within the $\mathrm{K} / \mathrm{Pg}$ boundary clay could have been produced by Trichoderma or similar soil fungi. Based on their studies of Trichoderma, Kubicek et al. (2019: 502) recently concluded that "the most likely interpretation of these data is therefore that Trichoderma was one of the fungal genera that participated in the strong burst in fungal populations that fed on the decaying biomass of the plants killed by the K/Pg." However, direct evidence for this event is limited (Kubicek et al., 2019). Accordingly, it is conceivable that this event might be recorded in the Aib signature of the K/Pg boundary clay.

\section{METHODS AND MATERIALS}

There is compelling evidence that Aib is present in the K/Pg boundary clay in the Starkville section of the Raton Basin, as first documented in the unpublished results of Moore's (1996) preliminary investigation and later confirmed by other researchers, who appear to have been unaware of Moore's study but nonetheless detected Aib in an essentially identical concentration (pmol/g) within the $\mathrm{K} / \mathrm{Pg}$ boundary clay (Pierazzo and Chyba, 1999; Becker et al., 2000; Pierazzo and Chyba, 2006). These researchers also documented Aib in the $\mathrm{K} / \mathrm{Pg}$ boundary clay at Sussex, Wyoming, in the Powder River Basin (Pierazzo and Chyba, 1999; Becker et al., 2000; Pierazzo and Chyba, 2006). However, the "Aib horizon" as it is referred to in this study has neither been correlated between these basins using a measured section, nor depicted graphically (Pierazzo and Chyba, 1999; Becker et al., 2000; Pierazzo and Chyba, 2006).

For the purpose of this study, the stratigraphic position of the Aib horizon described by Pierazzo and Chyba (1999), Becker et al. (2000) and Pierazzo and Chyba (2006) is illustrated in relation to the Cyathidites Couper fern-spore spike and maximum iridium anomaly (represented as a solid black line in Fig. 2). Measured sections for the Starkville and Sussex localities are drawn from Tschudy et al. (1984) and Nichols et al. (1992). These sections were then compared to the Moody Creek Mine section, which contains the K/Pg boundary fungal spike (Fig. 2) (Vajda and McLoughlin, 2004). In turn, each of these sections was cross-referenced with detailed descriptions provided in a comprehensive review by Nichols and Johnson (2008) to confirm the relative stratigraphic positions of the $\mathrm{K} / \mathrm{Pg}$ boundary clay to the fern-spore spike and maximum
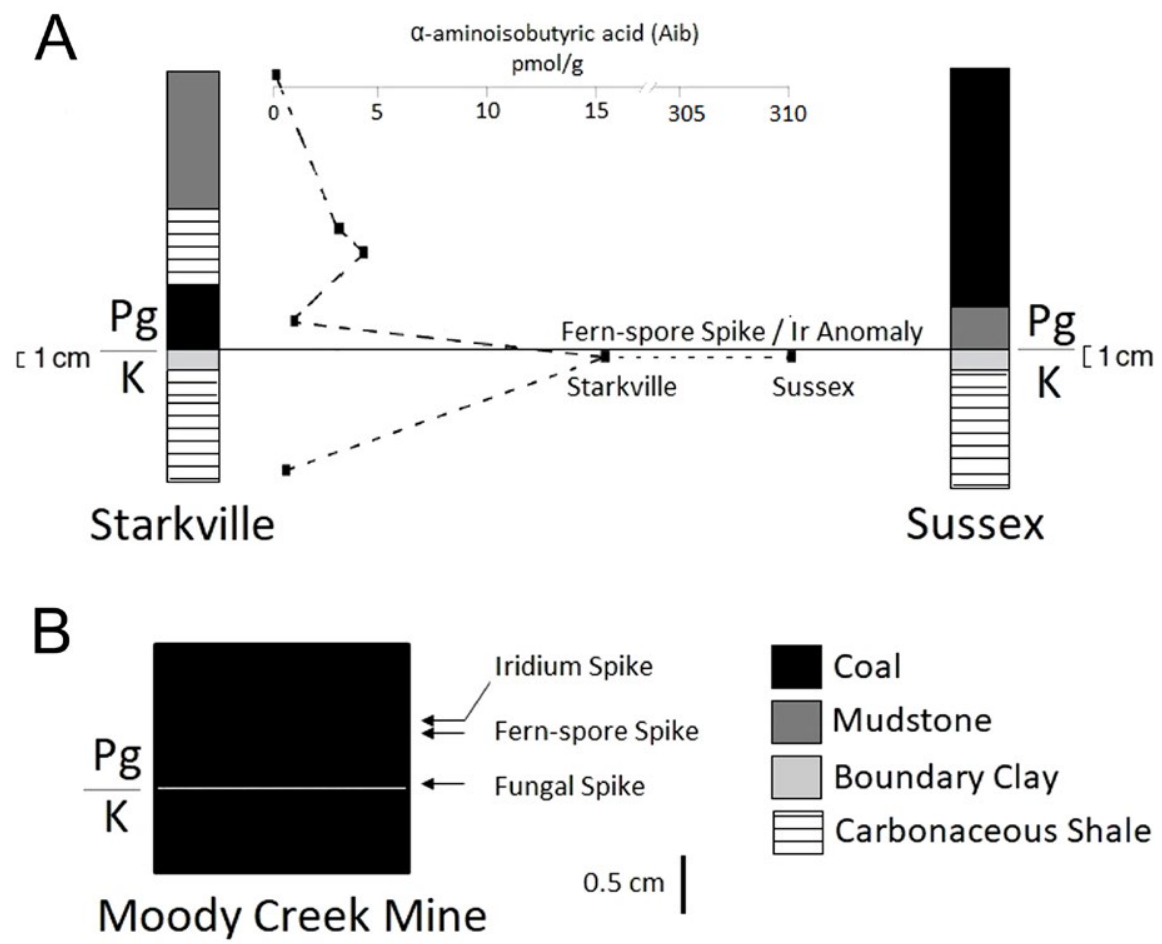

Fig. 2. A. Aib has been detected in the K/Pg boundary clay at Starkville, Colorado, and at Sussex, Wyoming, in the Raton and Powder River basins. The presence of Aib in the K/Pg boundary clay at Starkville was first documented by C.B. Moore (1996), who never published his results (reproduced here). A subsequent investigation by T. Bunch and A.L. Weber confirmed the presence of Aib in the K/Pg boundary clay at Starkville in essentially identical concentrations (Pierazzo and Chyba, 1999, 2006; Becker et al., 2000). Aib also was detected in the K/Pg boundary clay at Sussex, albeit in higher concentrations than at Starkville (Weber, 1998; Pierazzo and Chyba, 1999, 2006; Becker et al., 2000). The presence of Aib in the K/Pg boundary clay at these two localities has led numerous researchers to question the common assumption that Aib cannot survive large impact events (Pierazzo and Chyba, 1999, 2006; Becker et al., 2000). B. However, a fungal spike like that observed by Vajda and McLoughlin (2004) at the Moody Creek Mine locality in New Zealand could explain the presence of Aib in the K/Pg boundary clay at the Raton and Powder River basin localities 
iridium anomaly (i.e., iridium spike) as described in each of these studies (Tschudy et al., 1984; Nichols et al., 1992; Vajda and McLoughlin, 2004). The purpose of this exercise is to determine whether the relative stratigraphic positions of the fern-spore spike, iridium anomaly and Aib horizon can be correlated across these regions, in order to determine whether the Aib horizon might correspond with the fungal spike of Vajda and McLoughlin (2004).

Reviewing these data in the context of measured sections is critically important, as extraterrestrial Aib that survived and was deposited after the Chicxulub impact should be found in the so-called "fireball layer" (Kring and Durda, 2002), which also contains the maximum iridium anomaly and other residue from the fireball plume (Toon et al., 2016). At both Sussex and Starkville, the fireball layer directly overlies the $\mathrm{K} / \mathrm{Pg}$ boundary clay (Nichols and Johnson, 2008). The presence of Aib outside of this layer discounts the hypothesis that Aib was residue of the $\mathrm{K} / \mathrm{Pg}$ impact event (Kring and Durda, 2002). Moreover, omnipresence of Aib in trace amounts with peaks at specific horizons would appear to be more consistent with the sedimentary record of Aib-producing fungal blooms (Poirier et al., 2007) rather than with a single delivery resulting from an impact event (Kring and Durda, 2002). Although Moore (1996) reported trace concentrations of Aib at other horizons (Fig. 2A), these are not considered in the present analysis, because peerreviewed studies confirming the presence of an Aib horizon within the $\mathrm{K} / \mathrm{Pg}$ boundary clay at Starkville did not assess whether Aib can be detected throughout the section, only whether Aib is present in the $\mathrm{K} / \mathrm{Pg}$ boundary clay (Pierazzo and Chyba, 1999; Becker et al., 2000; Pierazzo and Chyba, 2006). Although Brisman et al. (2001) tentatively reported relatively high concentrations of Aib at other horizons at Starkville, these results were ambiguous and therefore are not considered in this study.

\section{DATA AND RESULTS}

It is well known that at Starkville South, the "most heavily sampled site in the Raton Basin" (Pillmore et al., 1999: 149), "the boundary claystone layer itself is completely barren of palynomorphs" (Nichols and Johnson, 2008: 109). This so-called "barren interval" of the K/Pg boundary clay at Starkville could be correlated with a similar interval in the Moody Creek Mine section, where no plant palynomorphs have been collected (Vajda and McLoughlin, 2004). This could provide a direct analog between the Aib-bearing K/Pg boundary clay at Starkville and the fungal spore-bearing horizon at Moody Creek Mine. However, the K/Pg boundary clay at Sussex is not barren and bears both latest Maastrichtian and earliest Danian plant palynomorphs (Nichols and Johnson, 2008). However, in all three sections the maximum iridium anomaly (i.e., iridium spike) and maximum fern-spore abundance (fern-spore spike) lie immediately above either the fungal spike (New Zealand) or the Aib horizon within the K/Pg boundary clay in the Raton and Powder River basins (Fig. 2). Therefore it may be possible to correlate the Aib horizon described by Pierazzo and Chyba (1999), Becker et al. (2000) and Pierazzo and Chyba (2006) in the Raton and Powder River basins with the fungal spike in New Zealand.

\section{DISCUSSION}

The stratigraphic position of the fungal spike described by Vajda and McLoughlin (2004) precisely matches the position of the Aib horizon described by Pierazzo and Chyba (1999), Becker et al. (2000) and Pierazzo and Chyba (2006) from the Raton and Powder River basins. According to these researchers, Aib has been detected within the K/Pg boundary clay in the Raton and Powder River basins - a determination consistent with an examination of the unpublished results of Moore (1996). If these reports are correct, then an Aib horizon is directly overlain by a fern-spore spike and maximum iridium anomaly. Thus the Aib horizon described by these authors could be correlated with Vajda and McLoughlin's (2004) fungal spike.

Pierazzo and Chyba (1999), Becker et al. (2000) and Pierazzo and Chyba (2006) all attribute the presence of Aib in the K/Pg boundary clay at these localities to the survival of organic molecules from the high-energy Chicxulub impact. As shown by the simulations of Pierazzo and Melosh (2000), however, the minimum shock pressures of the Chicxulub impact greatly exceeded the pressures $(\sim 30$ $35 \mathrm{GPa}$ ) known to completely destroy Aib in shock experiments (Bertrand et al., 2009; Cooper et al., 2013; Sugahara and Mimura, 2014). Moreover, the Aib horizon described by these authors does not correspond with the socalled "fireball layer", as would be expected if Aib were deposited by the Chicxulub impact (Alvarez et al., 1995; Kring and Durda, 2002). The thin fireball layer is represented in this study by the thin black line marking the $\mathrm{K} / \mathrm{Pg}$ boundary in Figure 2.

Based on contemporary research (Brückner et al., 2009; Elsila et al., 2011), a more likely explanation for Aib in these sections is 
that it was produced by fungi. An Aib horizon within the $\mathrm{K} / \mathrm{Pg}$ boundary clay is consistent with the interpretation that Aib-producing fungi such as Trichoderma thrived in the immediate aftermath of the $\mathrm{K} / \mathrm{Pg}$ impact event (Kubicek et al., 2019). In any case, this study is important because it is the first to propose that an Aib marker in the K/Pg boundary clay might be correlated with the fungal spike. Although Brückner et al. (2009) appear to have considered this possibility, they only discussed it in the context of the inconclusive study by Brisman et al. (2001), which was too poorly resolved to isolate or identify Aib in the $\mathrm{K} / \mathrm{Pg}$ boundary clay at Starkville. If correct, this hypothesis would bolster the interpretation that fungal spikes frequently accompany global mass-extinction events such as those observed at the Permian/Triassic and $\mathrm{K} / \mathrm{Pg}$ boundaries (Vajda and McLoughlin, 2007), and could provide an alternative approach to traditional palynological investigations for identifying the $\mathrm{K} / \mathrm{Pg}$ boundary fungal spike. However, it is important to point out in this context that Trichoderma is known to metabolize low-grade coal (Holker et al., 1999; Silva-Stenico et al., 2007), so production of Aib by modern fungi should not be ruled out, particularly if the $\mathrm{K} / \mathrm{Pg}$ boundary is found within coal.

There is, however, additional evidence for the proliferation of soil fungi during the $\mathrm{K} / \mathrm{Pg}$ mass-extinction event. Trichoderma and other soil fungi also produce gibberellic acid $\left(\mathrm{GA}_{3}\right)$ (Contreras-Cornejo, 2016; Kamalov et al., 2018). In earthworm casts, which contain these common fungi (Parle, 1963; Alauzet et al., 2001), the concentration of $\mathrm{GA}_{3}$ has been measured at 2000-3000 ppm (Tomati et al., 1988). Spores

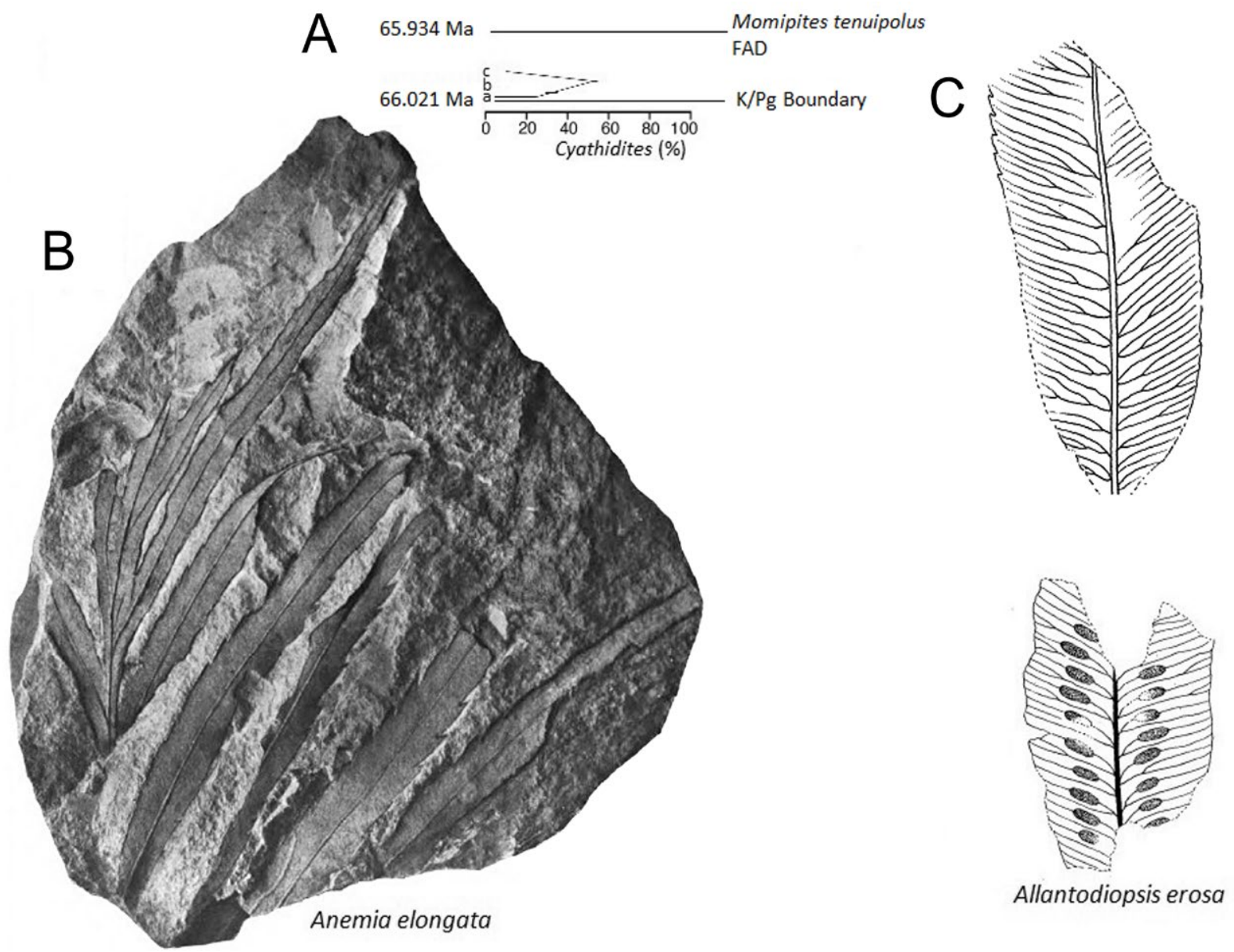

Fig. 3. A. Collections of Anemia-like schizaeaceous ferns (a, b, c) from southern Colorado and northeastern New Mexico coincide with Lyson et al.'s (2019) Cyathidites phase of the fern-spore spike. Lyson et al. (2019) collected A. elongata (Newberry) Knowlton (B) alongside Allantodiopsis erosa (Lesquereux) Knowlton et Maxon, an extinct asplenioid fern (C), from their lowest Danian plant assemblage, $2.75 \mathrm{~m}$ above the K/Pg boundary ( 10000 years after the K/Pg impact). Both of these ferns also crossed the $\mathrm{K} / \mathrm{Pg}$ boundary in the neighboring Raton Basin (Barclay et al., 2003; Berry, 2019a,b,c, 2020), and Anemia-like ferns were the most abundant pteridophyte in the lowest Paleocene section of the neighboring San Juan Basin (Flynn and Peppe, 2019). Therefore these are good candidates for Cyathidites-producing ferns and Laevigatosporites-producing ferns, respectively. Illustration of A. elongata adapted from Lee and Knowlton (1917: Plate 54, Fig. 2) from K/Pg boundary strata in the Raton Basin; illustrations of fertile and sterile foliage of A. erosa adapted from Knowlton (1930: Plate 4, Figs 1, 3) from Paleocene strata in the Denver Basin 
of the fern Anemia Sw. and its closest relatives are known to initiate germination in the dark (soils) under far lower concentrations of $\mathrm{GA}_{3}$ (Nester and Coolbaugh, 1986; Suo et al., 2015). However, spores of Laevigatosporitesproducing eupolypod ground ferns typically do not germinate in response to exposure to $\mathrm{GA}_{3}$ (Schneller, 2008; Suo et al., 2015).

In the area of this study, Anemia-like fern megafossils (Fig. 3) were among the first to recover from the $\mathrm{K} / \mathrm{Pg}$ impact (Berry, 2019a; Flynn and Peppe, 2019; Lyson et al., 2019). This is consistent with their production of psilate, trilete spores like those observed in the first (Cyathidites) phase of the fern-spore spike (Chandler, 1955, 1963; Berry, 2019a) and their presence in lowest Danian plant assemblages concomitant with the Cyathidites fernspore spike (Berry, 2019a; Lyson et al., 2019). Accordingly, it seems plausible that a spike in soil fungi could have been directly responsible for the earlier germination and proliferation of Anemia-like ferns observed in this study.

Based on study of the K/Pg boundary section at Starkville South, Tschudy et al. (1984) concluded that ferns were the first organisms to recolonize the denuded landscape immediately after the $\mathrm{K} / \mathrm{Pg}$ impact event, due to their propensity for rapid, long-distance dispersal by wind-blown spores. However, the results of this study alter this perspective. In accordance with the data from New Zealand, Aib-producing fungal saprotrophs thrived in the immediate wake of the $\mathrm{K} / \mathrm{Pg}$ mass-extinction event prior to the settling of soot and other aerosols from the atmosphere. Anemia-like ferns may have thrived during the earliest Danian as a direct result of this event.

\section{CONCLUSION}

As in the Southern Hemisphere, the K/Pg boundary sections at Starkville and Sussex in the Raton and Powder River basins may record evidence for a fungal spike at the $\mathrm{K} / \mathrm{Pg}$ boundary. As Starkville South was the first K/Pg boundary outcrop discovered to have a fernspore spike, this locality was instrumental in shaping Tschudy et al.'s (1984) interpretation of the tempo and mode of the earliest stage of terrestrial ecosystem recovery in western North America. Reevaluation of this record in light of a K/Pg boundary fungal spike changes this early perspective and corroborates the emerging alternative interpretation that a protracted $\mathrm{K} / \mathrm{Pg}$ impact winter delayed the recovery of ferns and other organisms from the soils (Berry, 2019b, c, 2020). However, future research should investigate whether an Aib spike coincides with the fungal spike in New Zealand and whether filamentous fungal spores can be recovered from the K/Pg boundary clay or other Aib-rich horizons within western North America.

\section{ACKNOWLEDGEMENTS}

I thank Tell and Miranda Berry for their patience and assistance with this project, and the anonymous reviewers for their valuable help in improving the manuscript.

\section{REFERENCES}

Alauzet, N., Roussos, S., Garreau, H., Vert, M., 2001. Microflora dynamics in earthworms casts in an artificial soil (biosynthesol) containing lactic acid oligomers. Brazilian Archives of Biology and Technology 44, 113-119.

Alvarez, W., Claeys, P., Kieffer, S.W., 1995. Emplacement of Cretaceous-Tertiary boundary shocked quartz from the Chicxulub crater. Science 269, 930-935.

Barclay, R., Johnson, K.R., Betterton, W.J., Dilcher, D.L., 2003. Stratigraphy and megaflora of a K-T boundary section in the eastern Denver Basin, Colorado. Rocky Mountain Geology 38(1), 45-71.

Becker, L., Poreda, R.J., Bunch, T.E., 2000. Fullerenes: An extraterrestrial carbon carrier phase for noble gases. Proceedings of the National Academy of Sciences, USA 97, 2979-2983.

Bercovici, A., Vellekoop, J., 2017. Methods in paleopalynology and palynostratigraphy: an application to the K-Pg boundary. In: Zeigler, K.E., Parker, W. (eds), Terrestrial depositional systems: decipherinc complexities through multiple stratigraphic methods. Elsevier, Cambridge, pp. 127-164.

Berry, K., 2019a. Linking fern foliage with spores at the K-Pg boundary section in the Sugarite coal zone, New Mexico, USA, while questioning the orthodoxy of the global pattern of plant succession across the K-Pg boundary. Neues Jahrbuch für Geologie und Paläontologie 291, 159-169.

Berry, K., 2019b. Fern spore viability considered in relation to the duration of the Cretaceous-Paleogene (K-Pg) impact winter. A contribution to the discussion. Acta Palaeobotanica 59, 19-25.

Berry, K., 2019c. Cyclosorus (Thelypteridaceae) s.l. from K-Pg boundary strata in central Colorado, USA: the oldest thelypteridaceous (cyclosoroid) fossils and their affinity to modern and fossil forms. 
Neues Jahrbuch für Geologie und Paläontologie, Abh. 293, 307-323.

Berry, K., 2020. A thelypteridaceous fern from the early Paleocene Raton Formation, south-central Colorado, and its importance in interpreting the climate of the region. Mtn Geologist 57, 5-20.

Bertrand, M., van der Gaast, S., Vilas, F., Hörz, F., Haynes, G., Chabin, A., Brack, A., Westall, F., 2009. The fate of amino acids during simulated meteoritic impact. Astrobiology 9, 943-951.

Brisman, K., Engel, M.H., Macko, S.A., 2001. Distribution, stereochemistry, and stable isotope composition of amino acids in K/T boundary sediments. Precambrian Research 106, 59-77.

Brückner, H., Becker, D., Gams, W., Degenkolb, T., 2009. Aib and Iva in the biosphere: neither rare nor necessarily extraterrestrial. Chemistry and Biodiversity $6,38-56$.

Brückner, H., Fox, F., Degenkolb, T., 2019. Sequences of acretocins, peptaibiotics containing the rare 1-Aminocyclopropanecarboxylic Acid, from Acremonium crotocinigenum CBS 217.70. Chemistry and Biodiversity 16, 1-16.

Chandler, M.E.J., 1955. The Schizaeaceae of the South of England in Early Tertiary times. Bulletin of the British Museum (Natural History) 2, 291-314.

Chandler, M.E.J., 1963. The lower Tertiary floras of southern England III: the flora of the Bournemouth beds; the Boscombe, and the Highcliff Sands. British Museum of Natural History, London.

Chin, K., Pearson, D., Ekdale, A.A. 2013. Fossil worm burrows reveal very early terrestrial animal activity and shed light on trophic resources after the end-Cretaceous mass extinction. PLoSONE 8, 1-8.

Contreras-Cornejo, H.A., Macías-Rodríguez, L., DelVal, E., Larsen, J., 2016. Ecological functions of Trichoderma spp. and their secondary metabolites in the rhizosphere: interactions with plants. FEMS Microbiology Ecology 92, 1-17.

Cooper, G., Horz, F., O’Leary, A., Chang, S., 2013. The impact and oxidation survival of selected meteoritic compounds: signatures of asteroid organic material on planetary surfaces. Lunar and Planetary Science Conference 44, 1868.

Elsila, J.E., Callahan, M.P., Glavin, D.P., Dworkin, J.P., Brückner, H., 2011. Amino acids from fungal peptaibiotics: assessing the potential for meteoritic contamination. Astrobiology 11, 123-133.

Flynn, A.G., Peppe, D.J., 2019. Early Paleocene tropical forest from the Ojo Alamo Sandstone, San Juan Basin, New Mexico, USA. Paleobiology 45, 612-635.

Goderis, S., Tagle, R., Belza, J., Smit, J., Montari, A., Erzinger, J., Claeys, P., 2013. Reevaluation of siderophile element abundances and ratios across the Cretaceous-Paleogene (K-Pg) boundary: implications for the nature of the projectile. Geochemica et Cosmochimica Acta 120, 417-446.

Hildebrand, A.R., Penfield, G.T., Kring, D.A., Pilkington, M., Camargo, A., Jacobsen, S.B., Boynton,
W.V., 1991. Chicxulub Crater: a possible Cretaceous/Tertiary boundary impact crater on the Yucatán Peninsula, Mexico. Geology 19, 867-871.

Holker, U., Ludwig, S., Scheel, T., Hofer, M., 1999. Mechanisms of coal solubilization by the deuteromycetes Trichoderma atrovide and Fusarium oxysporum. Applied Microbiology and Biotechnology 52, 57-59.

Kamalov, L.S., Turgunov, K.K., Aripova, S.F., Abdilamilov, O., 2018. Gibberellin A-3 from the microscopic fungus Trichoderma harzianum. Chemistry of Natural Compounds 54, 421-422.

Knowlton, F.H., 1930. The flora of the Denver Formation and associated formations of Colorado. USGS Professional Paper 155, 1-142.

Kring, D.A., Durda, D.D., 2002. Trajectories and distribution of material ejected from the Chicxulub impact crater: implications for postimpact wildfires. Journal of Geophysical Research 107, 6-1-6-22.

Kubicek, C.P., Steindorff, A.S., Chenthamara, K., Manganiello, G., Henrissat, B., Zhang, J., Cai, F., Kopchinskiy, A.G., Kubicek, E.M., Kuo, A., Baroncelli, R., Sarrocco, S., Noronha, E.F., Vannacci, G., Shen, Q., Grigoriev, I.V., Druzhinina, I.S., 2019. Evolution and comparative genomics of the most common Trichoderma species. BMC Genomics 20, 485-509.

Kyte, F.T., 1998. A meteorite from the Cretaceous/Tertiary boundary. Nature 396, 237-239.

Lee, W.T., Knowlton, F.H., 1917. Geology and Paleontology of the Raton Mesa and Other Regions, Colorado and New Mexico. USGS Professional Paper 109, 1-435.

Lyson, T.R., Miller, I.M., Bercovici, A.D., Weissenburger, K., Fuentes, A.J., Clyde, W.C., Hagadorn, J.W., Butrim, M.J., Johnson, K.R., Fleming, R.F., Barclay, R.S., MacCracken, S.A., Lloyd, B., Wilson, G.P., Krause, D.W., Chester, S.G.B., 2019. Exceptional continental record of biotic recovery after the Cretaceous-Paleogene mass extinction. Science 366, 977-983.

Martins, Z., Price, M.C., Goldman, N., Sephton, M.A., Burchell, M.J., 2013. Shock synthesis of amino acids from impacting cometary and icy planet surface analogues. Nature Geoscience 6, 1045-1049.

Mita, H., Shimoyama, A., Kajiwara, Y., 1996. Search for extraterrestrial amino acids in sediments at the Cretaceous/Tertiary boundary in Kawaruppu, Hokkkaido, Japan. Geochemical Journal 30, 89-98.

Moore, C.B., 1996. Amino acids in Cretaceous-Tertiary boundary outcrops in the Raton Basin. International Workshop Tunguska 96. University of Bologna, Bologna.

Nester, J.E., Coolbaugh, R.C., 1986. Factors influencing spore germination and early gametophyte development in Anemia mexicana and Anemia phyllitidis. Plant Physiology 82, 230-235.

Nichols, D.J., Brown, J.L., Attrep, M., Jr., Orth, C.R., 1992. A new Cretaceous-Tertiary boundary locality in the western Powder River Basin, Wyoming. Cretaceous Research 13, 3-30. 
Nichols, D.J., Johnson, K.R., 2008. Plants and the K-T Boundary. Cambridge University Press, Cambridge.

Ohno, S., Kadono, T., Kurosawa, K., Hamura, T., Sakaiya, T., Shigemori, K., Hironaka, Y., Sano, T., Watari, T., Otani, K., Matsui, T., Sugita, S., 2014. Production of sulphate-rich vapour during the Chicxulub impact and implications for ocean acidification. Nature Geoscience 7, 279-282.

Oró, J., Lazcano, A., Ehrenfreund, P., 2006. Comets and the origin and evolution of life. In: Thomas, P.J. et al. (eds), Comets and the Origin and Evolution of Life: Second Edition. Springer-Verlag, Berlin, pp. 1-28.

Parle, J.N., 1963. A microbiological study of earthworm casts. Journal of General Microbiology 31, 13-22.

Pierazzo, E., Chyba, C.F., 1999. Amino acid survival in large cometary impacts. Meteoritics and Planetary Science 34, 909-918.

Pierazzo, E., Chyba, C.F., 2006. Impact delivery of prebiotic organic matter to planetary surfaces. In: Thomas, P.J. et al. (eds), Comets and the Origin and Evolution of Life: Second Edition. SpringerVerlag, Berlin, pp. 137-168.

Pierazzo, E., Melosh, H.J., 2000. Hydrocode modeling of oblique impacts: the fate of the projectile. Meteoritics and Planetary Science 35, 117-130.

Pillmore, C.L., Nichols, D.J., Fleming, R.F., 1999. Field guide to the continental Cretaceous-Tertiary boundary in the Raton Basin, Colorado and New Mexico. GSA Field Guide 1, 135-155.

Poirier, L., Amiard, J.-C., Mondeguer, F., Quiniou, F., Ruiz, N., Pouchus, Y.F., Montagu, M., 2007. Determination of peptaibol trace amounts in marine sediments by liquid chromatography/electrospray ionization-ion trap-mass spectrometry. Journal of Chromatography A 1160, 106-113.

Quitté, G., Robin, E., Levasseur, S., Capmas, F., Rocchia, R., Birck, J.-L., Allègre, C.J., 2007. Osmium, tungsten, and chromium isotopes in sediments and in Ni-rich spinel at the K-T boundary: signature of a chondritic impactor. Meteoritics and Planetary Science 42, 1567-1580.

Röhrich, C.R., Iversen, A., Jaklitsch, W.M., Voglmayr, H., Berg, A., Dörfelt, H., Thrane, U., Vilcinskas, A., Nielsen, K.F., Döhren, H.V., Brückner, H., Degenkolb, T. 2012. Hypopulvins, novel peptaibiotics from the polyporicolous fungus Hypocrea pulvinata, are produced during infection of its natural hosts. Fungal Biology 116, 1219-1231.

Röhrich, C.R., Jaklitsch, W.M., Voglmayr, H., Iversen, A., Vilcinskas, A., Nielsen, K.F., Thrane, U., Döhren, H.V., Brückner, H., Degenkolb, T. 2014. Front line defenders of the ecological niche! Screening the structural diversity of peptaibiotics from saprotrophic and fungicolous Trichoderma/Hypocrea species. Fungal Diversity 69, 117-146.

Schneller, J.J., 2008. Antheridiogens. In: Ranker, T.A., Haufler, C.H. (eds), Biology and Evolution of Ferns and Lycophytes. Cambridge University Press, Cambridge, pp. 134-158.
Shukolyukov, A., Lugmair, G.W., 1998. Isotopic evidence for the Cretaceous-Tertiary impactor and its type. Science 282, 927-929.

Silva-Stenico, M.E., Vengadajellum, C.J., Janjua, H.A., Harrison, S.T., Burton, S.G., Cowan, D.A., 2007. Degradation of low rank coal by Trichoderma atroviride ES11. Journal of Indian Microbiology and Biotechnology 34, 625-631.

Sugahara, H., Mimura, K., 2014. Shock-induced pyrolysis of amino acids at ultra-high pressures ranged from 3.2 to $35.3 \mathrm{GPa}$. Journal of Analytical and Applied Physics 108, 170-175.

Suo, J., Chen, S., Zhao, Q., Shi, L., Dai, S., 2015. Fern spore germination in response to environmental factors. Frontiers in Biology 10, 358-376.

Tomati, U., Grappelli, A., Galli, E., 1988. The hormonelike effect of earthworm casts on plant growth. Biology and Fertility of Soils 5, 288-294.

Toon, O.B., Bardeen, C., Garcia, R., 2016. Designing global climate and atmospheric chemistry simulations for 1 and $10 \mathrm{~km}$ diameter asteroid impacts using the properties of ejecta from the K-Pg impact. Atmospheric Chemistry and Physics 16, 13185-13212.

Trigo-Rodríguez, J.P., 2006. The role of comets and meteorites in the origin of life. In: Seckbeck, J. (ed.), Life as We Know It. Springer, Berlin, pp. 383-397.

Trinquier, A., Birck, J.-L., Allègre, C.J., 2006. The nature of the KT impactor. A ${ }^{54} \mathrm{Cr}$ reappraisal. Earth and Planetary Science Letters 241, 780-788.

Tschudy, R.H., Pillmore, C.L., Orth, C.J., Gillmore, J.S., Knight, J.D., 1984. Disruption of the terrestrial plant ecosystem at the Cretaceous-Tertiary boundary, Western Interior. Science 225, 1030-1032.

Vajda, V., McLoughlin, S., 2004. Fungal proliferation at the Cretaceous-Tertiary boundary. Science, 1489.

Vajda, V., McLoughlin, S., 2007. Extinction and recovery patterns of vegetation across the CretaceousPalaeogene boundary - a tool for unraveling the causes of the end-Permian mass-extinction. Review of Palaeobotany and Palynology 144, 99-112.

Vajda, V., Ocampo, A., Ferrow, E., Bender Koch, C. 2015. Nanoparticles as the primary cause for longterm sunlight suppression at high southern latitudes following the Chicxulub impact. Gondwana Research 27, 1079-1088.

Weber, A.L., 1998. Prebiotic polymer synthesis and the origin of glycolytic metabolism. Final Technical Report, NASA Cooperative Agreement NCC 2-784, SETI Institute, Mountain View, 1-102.

Whittet, D.C.B., 1997. Is extraterrestrial organic matter relevant to the origin of life on Earth? Origins of Life and Evolution of the Biosphere 27, 249-262.

Zahnle, K., Grinspoon, D., 1990. Comet dust as a source of amino acids at the Cretaceous/Tertiary boundary. Nature 348, 157-160.

Zhao, M., Bada, J.L., 1989. Extraterrestrial amino acids in the Cretaceous/Tertiary boundary sediments at Stevns Klint, Denmark. Nature 339, 463-465. 